\title{
Frostwing Co-Operation in Aircraft Icing Research
}

\author{
o Pekka Koivisto, Aalto University, Helsinki, Finland \\ o Erkki Soinne, Finnish Transportation Safety Agency (TRAFI), Helsinki, Finland \\ o Andy Broeren, NASA Glenn Research Center \\ o Thomas Bond, U.S. Federal Aviation Administration
}

\begin{abstract}
The aerodynamic effects of Cold Soaked Fuel Frost have become increasingly significant as airworthiness authorities have been asked to allow it during aircraft take-off. The Federal Aviation

Administration and the Finnish Transport Safety Agency signed a Research Agreement in aircraft icing research in 2015 and started a research co-operation in frost formation studies, computational fluid dynamics for ground de/anti-icing fluids, and de/anti-icing fluids aerodynamic characteristics. The main effort has been so far on the formation and aerodynamic effects of CSFF. To investigate the effects, a generic high-lift common research wind tunnel model and DLR-F15 airfoil, representing the wing of a modern jet aircraft, was built including a wing tank cooling system. Real frost was generated on the wing in a wind tunnel test section and the frost thickness was measured with an Elcometer gauge. Frost surface geometry was measured with laser scanning and photogrammetry. The aerodynamic effect of the frost was studied in a simulated aircraft take-off sequence, in which the speed was accelerated to a typical rotation speed and the wing model was then rotated to an angle of attack used at initial climb. Time histories of the lift coefficient were measured with a force balance. The experiments showed that depending on the ambient temperature the frost may evaporate/melt during the take-off sequence. Lift losses after rotation with CSFF contamination at ambient temperatures of $4^{\circ}$ to $7^{\circ} \mathrm{C}$ above freezing point were measured to be 4 to $5 \%$ for roughness values, k/c, below $10^{-3}$. For comparison, lift loss tests with typical anti-icing fluids were performed resulting to roughly equal lift losses. This paper gives an overview of the performed activities.
\end{abstract}

\section{Introduction}

Accidents and incidents have been caused by the degradation of aircraft aerodynamic performances, reduction of safety margins and reduction of maneuverability/controllability due to airframe ground icing contamination or inadequate de-/anti-icing operations. The European Aviation Safety Agency EASA has received a number of safety recommendations in this respect and it is therefore proposed to review the existing certification specifications and acceptable means of compliance. For this purpose, EASA has formed a Rule making Task RMT.0118 [1]. The objective of the task is to mitigate the risk of loss of control of an airplane in particular during the take-off phase caused by an aerodynamic performance or controllability degradation, as a result of aerodynamic surfaces contamination by ice or de/anti-icing fluids. To achieve this objective, it shall be

Page 1 of 12 considered to amend the existing certification specifications. Any hazardous safety effect must be mitigated by the applicant through acceptable design and/or operational means. The FAA and the Finnish Transport Safety Agency (Trafi) have representation in the rule making task force.

Cold Soaked Fuel Frost (CSFF) is formed on an aircraft wing tank area on the ground when the aircraft has been at high altitude where the wing structure and fuel have been cooled down. Frost formation depends on ambient temperature, humidity and other factors such as wind speed causing forced convection. A literature review on CSFF formation is presented by Koivisto [2]. The phenomenon is known by aircraft manufacturers, airlines, and the authorities, but there are only a few publications with real frost related to aircraft. Ljungsröm [3] performed wind tunnel tests on NACA $65_{2}$-A215 airfoil with abrasive paper to simulate the effect of hoar frost in representative take-off configurations with and without a flap and slat. Artificial copies of hoar frost were made by Kind and Lawrysyn [4] and tested in a wind tunnel on a flat plate to investigate the effect of frost on the boundary layer. According to Bragg et al [5] frost on an airfoil lower surface, simulated with distributed roughness particles, is significant only when it exists far enough forward to affect the upper surface boundary layer. The effects of distributed roughness were studied by Khodadoust et al [6] and Valarezo et al [7] on multi-element airfoils in flight. Boer and van Hengst [8] studied the effect of distributed roughness due to ground icing on a multi-element airfoil. Effects of CSFF have been studied by Koivisto ( [9] and [10]) using a cooled wind tunnel model and real frost on two generic jet aircraft wing airfoils, the Boeing designed generic high-lift common research model [11] (HL-CRM - Mod) and an Airbus type DLR-F15 airfoil [12].

Cold Soaked Fuel Frost is of interest for the next take-off after a turn around. Traditionally the Federal Aviation Administration of the United States has required in the operative regulation [13] paragraph 121.629(b) that "No person may take off an aircraft when frost, ice, or snow is adhering to the wings...Takeoffs with frost under the wing in the area of fuel tanks may be authorized by the Administrator”. In other words, a clean wing concept has been required on the wing upper surface. The European Aviation Safety Agency has a different approach in the operative regulation [14] CAT.OP.MPA.250(b), where it says that "The commander shall only commence take-off if the aircraft is clear of any deposit that might adversely affect the performance or controllability of the aircraft”. So EASA allows contamination when it does not adversely affect operation of the aircraft. Transport Canada allows contamination on the wing in take- 
off in the same way as EASA, provided that there is no adverse effect. At present there is an EASA and Transport Canada approval for the Boeing 737NG aircraft to perform a take-off with certain amount of CSFF on the wing upper side. The FAA has also given an exemption for this aircraft.

\section{Frostwing Research Co-Operation}

The FAA and Trafi have a framework Research Agreement, signed in 2015, on aircraft icing research with an emphasis on ground icing such as the effects of anti-icing fluids and CSFF. The research cooperation of the FAA and Trafi was performed under the title Frostwing reflecting the main emphasis of work. The two agencies had somewhat different overlapping interests of research and this was considered in the respective budgeting. The same research facilities were used, and the costs were shared in the proportion of the budgets. This worked well, and the joint project lead made the decisions together. However, the different time zones and the trans-Atlantic cooperation required a special planning.

The other participants in the project were Arteform Ltd, which performed the wind tunnel tests and manual laser scanning, Dimensium Ltd and National Land Survey of Finland (photogrammetry and post processing of laser and photogrammetry results) and NASA with a special competence in wind tunnel testing, laser scanning and the post processing of the laser results.

\section{Research Topics}

Within the Frostwing research co-operation the following research topics were studied:

\author{
Cold Soaked Fuel Frost \\ Frost formation \\ Elcometer measurement of thickness \\ Laser imaging \\ Photogrammetry \\ Lift degradation \\ Boundary layer displacement thickness
}

Computational fluid dynamics for ground de/anti-icing fluids Fluids on a flat plate

De/anti-icing fluids aerodynamic characteristics

Wind tunnel tests of fluids on a flat plate

Wind tunnel tests on an airliner wing section

Secondary wave tests on an airliner wing section

There are three Trafi reports on CFD calculations and one report on wind tunnel tests on de/anti-icing fluids on a flat plate found on home page:

https://www.traficom.fi/fi/tilastot-ja-julkaisut/julkaisut under the heading "Trafin tutkimuksia”. There is a publication on the secondary wave effects Koivisto et al [15] and frost photogrammetry Soinne and Rosnell [16].

This paper concentrates on the fluids and Cold Soaked Fuel Frost wind tunnel tests on the wing section models. The methods used for the studies of CSFF formation are described. The aerodynamic measurements of CSFF and anti-icing fluid effects are described in detail followed by a discussion on the results.

\section{Cold Soaked Fuel Frost studies}

\section{Photographic Documentation}

The growth of Cold Soaked Fuel Frost on a wing section was one of the main research interests of the FAA. The frost formation was documented with time- lapse photography during the formation process and still photography at the conclusion of the frost-growth period. Elcometer thickness measurements and laser scanning were also performed at the end of the frost growth period prior to aerodynamic investigations.

\section{Elcometer Measurements}

The Elcometer gauge is a mechanical device used for frost thickness measurements (Fig.1). The aluminum disc has gauge edges at different heights and putting the gauge in contact with the wing surface one can see from the gauge marks in the frost where contact has been reached. The Elcometer measurements should in principle give a thickness value close to the maximum frost thickness, but comparisons with photogrammetry results showed that the value tends to be between the maximum and average thickness values determined by photogrammetry. It may be so, that a certain number of frost crystal peaks need to be in contact with the gauge before it is seen that a contact has been made. Elcometer measurements were made at twelve locations on the wing section upper surface. An average value and a standard deviation was calculated from the measured values. The standard deviation was about $16 \%$ to $25 \%$ of the average thickness values.

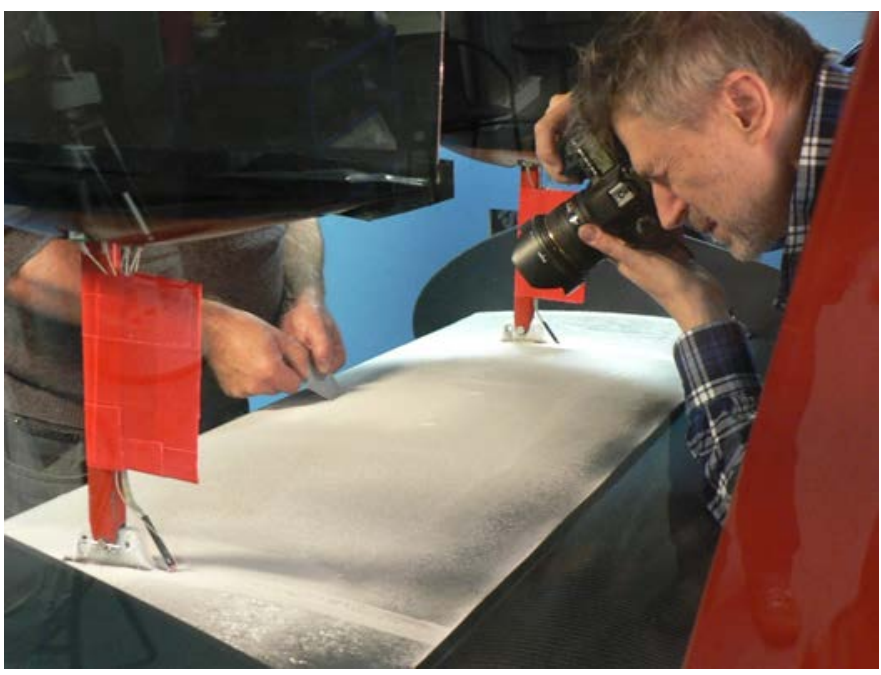

Figure 1. Frost thickness measurement with Elcometer gauge on HL- CRM Mod wing section model upper surface.

\section{Laser Scanning}

Three-dimensional laser scanning was performed to measure the frost thickness and roughness level. Prior to this research effort with CSFF, NASA adapted commercial scanning equipment for ice accretion measurement including small roughness [17], [18]. In addition, McClain et al., [19] have developed and implemented roughness and thickness characterization methods for small ice roughness from laser scan data. These characterization methods should be applicable to the frost generated in this research. Quantification of frost in this way could allow for follow-on 
aerodynamic research using computational or experimental approaches. In the latter application, artificial frost could be fabricated with a high degree of fidelity and applied to another windtunnel model for aerodynamic testing at representative scales, Reynolds numbers and Mach numbers.

The 3D scanning was performed using a Romer Absolute Arm 7530SI that was carried into the wind-tunnel test section at the conclusion of a frost growth period [Fig. 2]. The frost area to be scanned was treated with a special paint formulated to increase the reflectivity of the frost surface. The paint was applied using an automotive-style spray gun with special care so as not to damage the rather delicate dendritic features of the frost morphology. Some frost scans were also performed without painting the surface for comparison purposes. The scanning was performed by manually moving the scanner head over the area of interest in two perpendicular directions. A reference scan of the clean, or unfrosted surface was also performed at the same environmental conditions. This approach allowed for a direct comparison between the frost surface with the clean wing surface.

Post processing of the scan data was done using Geomagic software and the point count was reduced from about 30 to 1 million points. The unpainted frost scan data could not be post-processed, because there were too many flaws in the scan data such as "holes" or "gaps" and reversed surface normals. The painted frost scan data was successfully post-processed and aligned to clean wing reference surface. A section was cut through the clean wing and frost surface, see Figure 3. It appears that this method generated a quantitative measure of the frost thickness and surface roughness. The section cut shows approximately $1 \mathrm{~mm}$ average frost thickness with peaks up to about $2 \mathrm{~mm}$. These values include the thickness of the ice accretion paint which was about $0.2 \mathrm{~mm}$. [16]

\section{Aerodynamic Test Setup}

\section{Wind Tunnel}

Aalto University Low Speed Wind Tunnel is a closed circuit wind tunnel with test section dimensions of $2 \mathrm{~m} \times 2 \mathrm{~m}$ and test section length of $4 \mathrm{~m}$. The flow uniformity in the test section is $<3.4 \%$, and turbulence level $<0.28 \%$ at the wind tunnel speed of $60 \mathrm{~m} / \mathrm{s}$. However, during acceleration the turbulence level is somewhat higher, around $0.35 \%$. The turbulence level is relevant when a clean airfoil reference test is made. When the airfoil is contaminated (with frost or anti-icing fluid) it is not too sensitive for the tunnel turbulence level as the boundary layer is already much disturbed by the contamination.

The massive concrete structures of the wind tunnel ducts are outside the facility building. This makes the tunnel structure during winter time an efficient heat sink and the fan power dissipated during short period take-off run simulation does not increase the test section temperature significantly (less than $2{ }^{\circ} \mathrm{C}$ ). Temperatures in the test section follow roughly the daily outside air temperature (OAT) which during the winter time are suitable for deicing/anti-icing fluid tests (near or below $0^{\circ} \mathrm{C}$ ). During the tests of this study the wind tunnel air temperature varied between $-5^{\circ} \mathrm{C}$ and $+8^{\circ} \mathrm{C}$.

\section{Wind Tunnel Models}

The wing section model geometries have been chosen to represent modern airline wing sections. The geometries of the wing sections Page 3 of 12

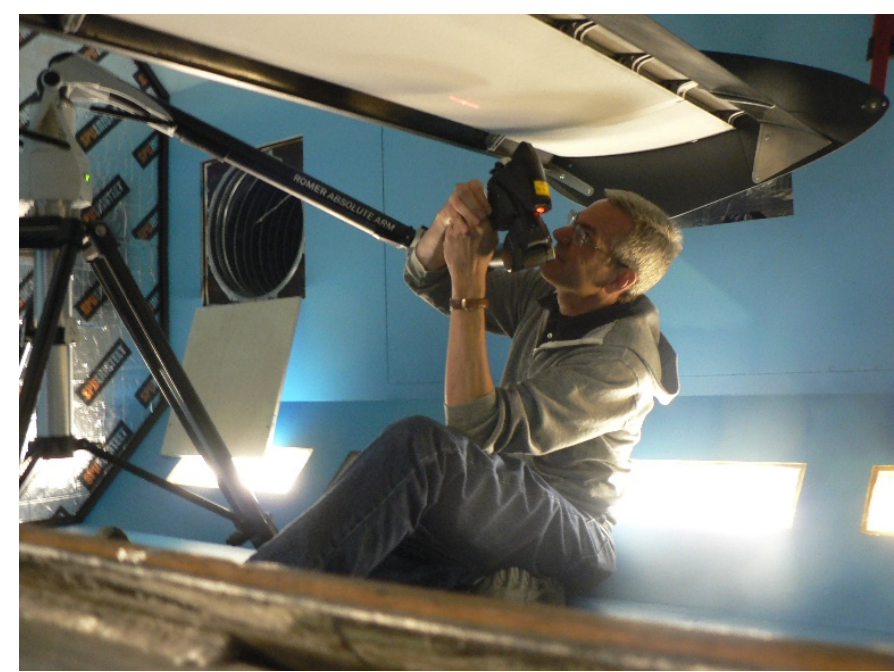

Figure 2. Laser scanning of frost on HL-CRM Mod wing section model lower surface.

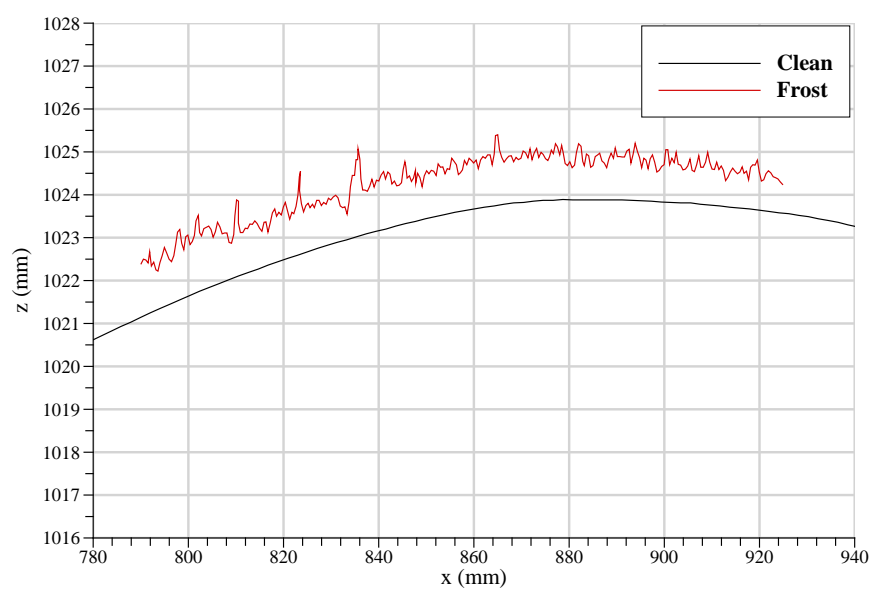

Figure 3. Example section of scanned clean wing and frost surfaces.

are illustrated in Figure 4. The main dimensions and other relevant information are collected in Table 1. Both models were equipped with slats and flaps to enable a take-off configuration simulation. As the wing models were intended to be 2D neither of them incorporated sweep or twist.

The DLR-F15 geometry was delivered as unambiguous 2D coordinates, however, the HL-CRM Mod data were in the form of 3D wing geometry which implied some analysis on the representative section of the wing. A representative wing section was selected in a local upper surface streamline direction to give a representative upper surface pressure distribution. The section was taken in the vicinity of the wing Mean Aerodynamic Chord free from the wing kink and engine.

The wing models were mounted to a three-component balance to measure the aerodynamic lift, drag and pitching moment. The balance setting design enabled the model to be rotated during the wind tunnel runs to simulate the take-off sequence. The models were equipped with endplates to minimize the three dimensionality of the flow (Figure 5 and 7). A reasonable two dimensionality and absence of flow separations were confirmed by tufts. Slats and flaps 

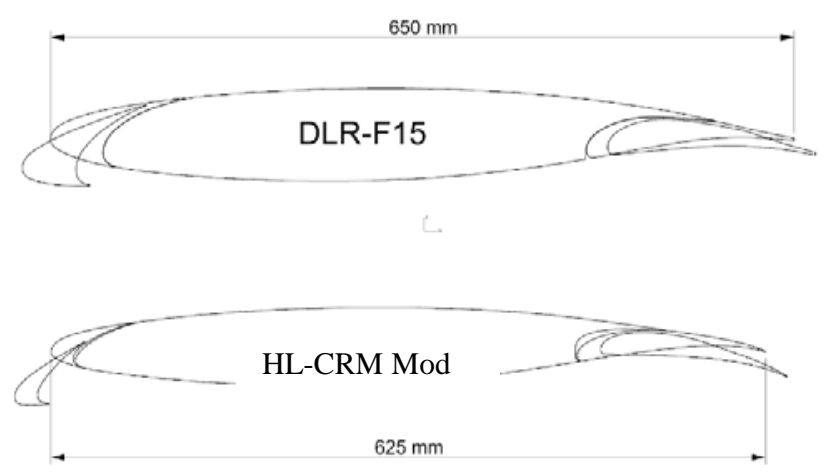

Figure 4. The two wing sections used in the wind tunnel tests of the present study. Clean and selected take-off configurations presented - DLR-F15: slat $11^{\circ}$, flap $5^{\circ}$, HL-CRM Mod: slats $22^{\circ}$, flaps $10^{\circ}$.

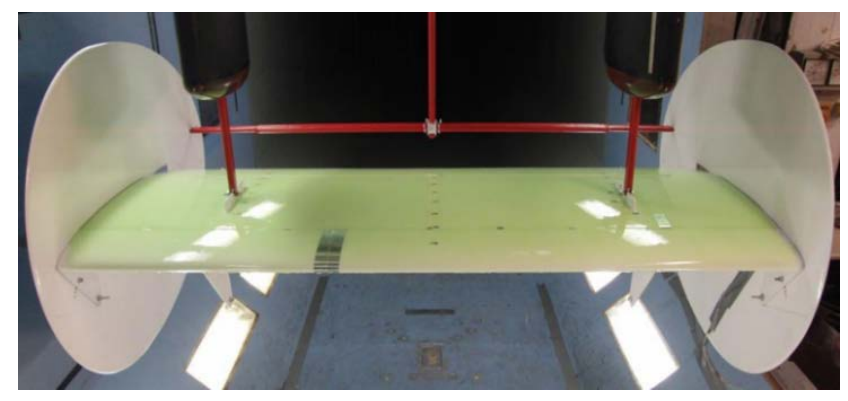

Figure 5. Wing section model DLR-F15 in the wind tunnel after an anti-ice treatment.

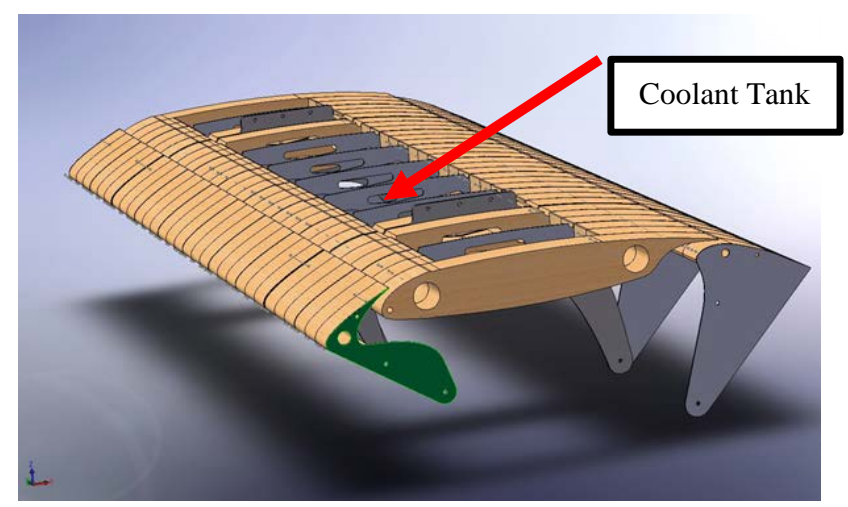

Figure 6. Structure and the coolant tank of the DLR -F15 wing section model

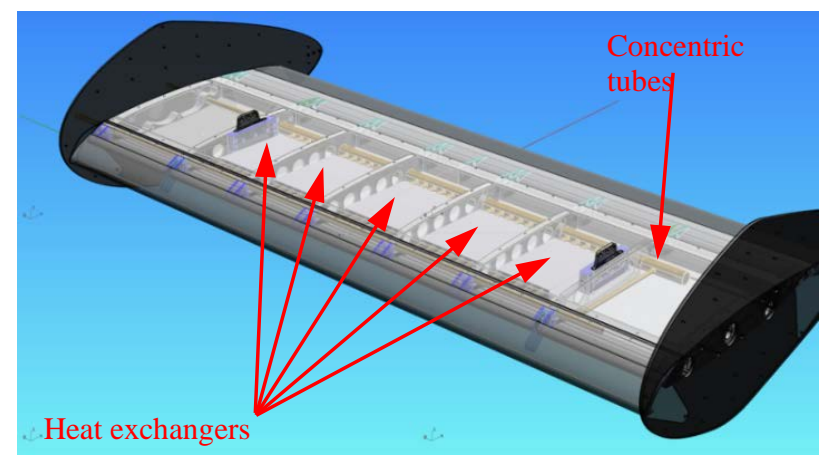

Figure 7. Structure and the coolant tank of the HL-CRM Mod wing section model

Page 4 of 12 were adjustable in both models to enable simulation of the real operational sequence where the flaps and slats are extended after antiicing treatment just prior to the take-off.

The wing models were equipped with glycol coolant tanks to simulate the effect of cold fuel in a wing tank [Figure 6 and 7] In DLR-F15 model the tank was cooled down taking the wing model into a deep freezer before mounting it to the test section. For HLCRM Mod model there was a separate cooling system designed to keep the fuel tank area cool. The coolant tank temperature was monitored for both models via a temperature sensor inside the coolant tank. The surface material on the tank area was painted aluminum in both models whereas the other parts of the wing model in DLR-F15 consisted of ureol blocks with the same surface paint as in the tank area. The HL-CRM-Mod model was an aluminum construction with the slat and flap made of carbon fiber. The positions of the wing model coolant tanks tank are collected into Table 1.

Table 1. Information on the wing models selected to the study.

\begin{tabular}{|c|c|c|c|c|c|}
\hline $\begin{array}{c}\text { Wing } \\
\text { section }\end{array}$ & $\begin{array}{c}\text { Chord } \\
{[\mathrm{m}]}\end{array}$ & $\begin{array}{c}\text { Span } \\
{[\mathrm{m}]}\end{array}$ & $\begin{array}{c}\text { Area } \\
{\left[\mathrm{m}^{2}\right]}\end{array}$ & $\begin{array}{c}\text { Thickness } \\
{[\%]}\end{array}$ & $\begin{array}{c}\text { Fuel Tank Position } \\
{[\mathrm{x} / \mathrm{c}]}\end{array}$ \\
\hline DLR-F15 & 0.65 & 1.50 & 0.975 & 15.0 & $0.215-0.615(0.4 \mathrm{c})$ \\
\hline $\begin{array}{l}\text { HL-CRM } \\
\text { Mod }^{10}\end{array}$ & 0.63 & 1.55 & 0.969 & 10.9 & $0.120-0.650(0.53 \mathrm{c})$ \\
\hline
\end{tabular}

\section{Aerodynamic Test Methodology}

\section{Take-off Sequence}

Considering anti-icing fluid or CSFF induced wing contamination performance degradation the most critical condition is the One Engine Inoperative (OEI) situation where the airliner is flying at the take-off safety speed, $\mathrm{V}_{2}$, after lift-off up to the so called cleaning altitude at which the flaps and slats are retracted ( $>400 \mathrm{ft}$ above ground level as per EASA CS 25.121 [20]). As the performance degradation due to anti-icing treatment has practically diminished well before reaching the cleaning altitude the relevant phases of flight regarding performance degradation are the take-off roll and initial climb at speed $\mathrm{V}_{2}$.

While developing the Aerodynamic Acceptance Test (AAT), Hill and Zierten [21] evaluated five specific take-off performance criteria following the FAR 25 requirements:

- Adequate margin between $1 \mathrm{~g}$ stall speed $\left(\mathrm{V}_{\mathrm{s} 1 \mathrm{~g}}\right)$ and takeoff safety speed $\mathrm{V}_{2}$

- $\quad$ Adequate margin between minimum unstick and lift-off speed

- $\quad$ Adequate aft body-runway clearance during take-off

- $\quad$ Adequate take-off acceleration and climb capabilities

- $\quad$ Adequate maneuver capability to stall warning

Hill and Zierten determined that the most critical of these five criteria was maintaining an adequate margin between the $1 \mathrm{~g}$ stall speed and 
$V_{2}$. To ensure a safe operation when the fluids are used they selected a criteria requiring a $\mathrm{V}_{2}$ that is at least $1.1 \mathrm{~V}_{\mathrm{s} 1 \mathrm{~g}}$ compared to the FAR 25 requirement of $1.13 \mathrm{~V}_{\mathrm{s} 1 \mathrm{~g}}$. Reducing the margin to stall from $13 \%$ to $10 \%$ implies a corresponding lift loss of $5.24 \%$. The algebraic analysis behind this reasoning is given e.g. by Broeren and Riley [22]. Since Hill and Zierten's classical work there have been regulatory changes to certification standards. EASA CS 25.105 (take off) and CS 25.121 (climb) give presently an allowance of $3 \%$ (or 3 KCAS) decrement to stall speed in icing conditions which would then lead to lift loss of $5.74 \%$.

The assessment of the effect of anti-icing treatment and CSFF contamination on the wing was in this study decided to be done in line with the research work done while developing the present AAT. For this reason, the wind tunnel tests were designed to simulate the take-off as follows: the wind tunnel is first accelerated from idle speed to a preselected "rotation" speed with constant angle of attack simulating the ground roll after which the wind tunnel speed is maintained constant and the wing model is rotated to a preselected angle-of attack corresponding to $\mathrm{V}_{2}$. This situation is maintained for 30 to 60 seconds followed by decelerating the wind tunnel to a halt. During the wind tunnel run aerodynamic coefficients are measured, particularly the lift coefficient. The lift loss due to the contamination is then the main parameter to assess.

It should be noted that the above mentioned 5.24\% lift loss refers to the maximum lift coefficient for a three dimensional aircraft or wind tunnel model whereas the present study considers a two dimensional wing section at a $\mathrm{C}_{1}$ corresponding to $\mathrm{V}_{2}$. Determining the correlation between the three dimensional wing maximum lift degradation and the two dimensional lift degradation at an angle of attack corresponding to speed $\mathrm{V}_{2}$ is considered to be beyond the scope of the present study. However, the criteria for contamination effects will be assessed in this study via the lift loss percentage.

To find a satisfactory combination of angle of attack and lift coefficient for the wing models both during simulations of ground roll and flight at speed $V_{2}$, several different slat and flap configurations were tested. Speed $\mathrm{V}_{2}$ was limited to $60 \mathrm{~m} / \mathrm{s}$ by the wind tunnel practical maximum speed. After a set of extensive tests, the best wing configurations described in Table 2 were selected. Table 2 also includes the selected angle of attacks corresponding lift coefficients during the wind tunnel simulations for take-off. The analysis and reasoning behind these figures are described in detail by Koivisto [23]. The speed $V_{2}$ was selected to be the practical maximum speed $60 \mathrm{~m} / \mathrm{s}$ of the wind tunnel. The time used to accelerate the wind tunnel speed to $60 \mathrm{~m} / \mathrm{s}$ was selected to be $30 \mathrm{~s}$ as per AAT [24]. The Reynolds number corresponding to $V_{2}=60 \mathrm{~m} / \mathrm{s}$ is $0.3 \times 10^{6}$ using an average chord length of the two models.

Table 2. Wing section configurations, angle of attacks and lift coefficients

\begin{tabular}{|c|c|c|c|c|c|}
\hline $\begin{array}{c}\text { Wing } \\
\text { section }\end{array}$ & $\begin{array}{c}\text { Slat/Flap } \\
\text { angle }\end{array}$ & $\begin{array}{c}\text { Ground } \\
\text { Roll } \alpha\end{array}$ & $\begin{array}{c}\text { Ground } \\
\text { Roll } \mathrm{C}_{1}\end{array}$ & $\alpha$ at $\mathrm{V}_{2}$ & $\mathrm{C}_{1}$ at $\mathrm{V}_{2}$ \\
\hline $\mathrm{DLR}-\mathrm{F} 15$ & $\mathrm{~S} 11^{\circ} / \mathrm{F}^{\circ}$ & $0^{\circ}$ & 0.51 & $8.0^{\circ}$ & 1.28 \\
\hline $\begin{array}{c}\mathrm{HL}-\mathrm{CRM} \\
\text { Mod }\end{array}$ & $\mathrm{S} 22^{\circ} / \mathrm{F} 10^{\circ}$ & $0^{\circ}$ & 0.52 & $9.2^{\circ}$ & 1.50 \\
\hline
\end{tabular}

\section{Measurement of Lift}

A standard measuring software collects the wind tunnel temperature, airspeed, dynamic pressure, relative humidity, balance forces and moments and wing angle of attack. The temperatures of the cooling tank were measured separately to record the mean temperatures during each test.

For qualitative analysis of the fluid flow off and CSFF melting and sublimation process the test runs were videoed through a Plexiglas window on the ceiling of the test section.

The initial mean thicknesses of fluid layers were defined by pointwise measurements (27 evenly spaced points) of film thickness using the Elcometer thickness gauge. The resolution of the thickness gauge was 25 to $50 \mu \mathrm{m}$ depending on the scale. The maximum effect of mass of the applied fluid on the measured lift values was less than $0.1 \%$ of the lift force. Moreover, most of the fluid has left the upper surface at the significant point of rotation which means the effect of fluid mass is insignificant in this study.

The initial mean thicknesses of the frost layers were measured using the same thickness gauge as in the fluid tests. There were altogether 12 measuring points on the tank area. With the mean frost thickness values varying between the tests from $0.055 \mathrm{~mm}$ to $2.250 \mathrm{~mm}$ the standard deviation per 15-point measurement case varied from 0.002 $\mathrm{mm}$ to $1.220 \mathrm{~mm}$. A uniform frost layer turned out to be very difficult to create.

The effect of different anti-icing treatments or CSFF on the take-off performance was evaluated by measuring the lift coefficient degradation $\Delta \mathrm{C}_{1}$ due to the contamination. This means sequential $\mathrm{C}_{1}$ measurements of an uncontaminated (cleaned) wing and a contaminated wing (fluid or frost). As the result is a difference between the two lift coefficients at the same angle of attack the repeatability of the tests is more relevant than the absolute accuracy of the lift coefficient itself.

The lift coefficient measurements for an uncontaminated DLR-F15 wing gave well repeatable results at the fixed take-off angle of attack. For 20 separate clean wing tests the lift coefficient mean value was 1.281 with a standard deviation of 0.0028 , which gives a coefficient of variation of $0.219 \%$. For an anti-ice treated wing the lift coefficient repeatability was not as good. Just after rotation the standard deviation of lift coefficient for 2 to 4 runs with similar antiicing treatment varied between 0.005 and 0.01 . The obvious reason for higher standard deviation figures is the difficulty to repeat all the conditions of the fluid applications. As it was not possible to end up with two similar frost layers the repeatability of the measurements was not possible to define. The repeatability of the lift coefficient of uncontaminated HL CRM Mod wing section model was also assessed. The 12 measurements done for uncontaminated wing at take-off angle of attack the lift coefficient mean value was 1.501 with a standard deviation of 0.0037 which gives a coefficient of variation of $0.247 \%$. When two lift coefficient values are measured it is possible that both errors have the same sign or opposite signs resulting in an error on the difference of 0 and 0.0074 respectively. Often a combined error, caused by several independent factors, is estimated using a root mean square value of the individual errors. The difference of two lift coefficients will then have a standard deviation of $\sqrt{2} * 0,247=0.349 \%$. This is still a good measurement accuracy on CSFF and anti-icing effects which are in the vicinity of $5 \%$. 


\section{Wind Tunnel Results and Discussion}

\section{Clean Wing Model}

The attainable range of lift coefficients for the take-off simulation tests was a tradeoff between contradicting requirements. There was a need for a chord large enough to reach a reasonable Reynolds number. Also, the slot dimensions for flaps and slats had to be large enough to get the fluids flowing without clogging. The restricting factor was the balance limit load (with a reasonable margin) for the lift force. This constrained the maximum lift coefficient during the tests to be below the ideal value.

For the same reason it was impossible to reach the stall with rotation speed of $60 \mathrm{~m} / \mathrm{s}$. Stall with lower speeds would have led to considerably lower Reynolds numbers and an inconsistent anti-icing fluid behavior. As the chord of the model was large relative to the wind tunnel test section the stall situation was not considered to be risk free regarding the wind tunnel diffusor flow. The lift coefficient variations with angle of attack for the wing section models in the configurations described in Table 2 are presented in Figure 8. There is some nonlinearity in the HL-CRM Mod slope.

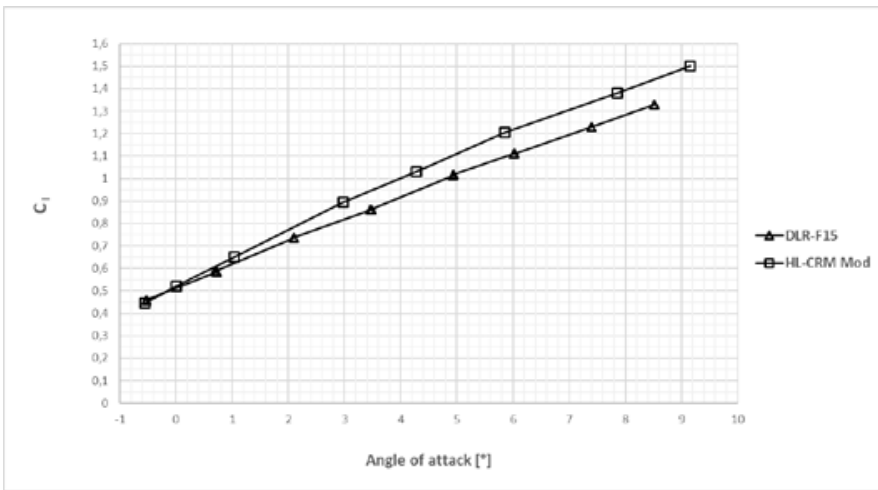

Figure 8. Lift coefficient variation with angle of attack at speed of $60 \mathrm{~m} / \mathrm{s}$ (Re $2.910^{6}$ ). Wing section configurations as presented in Table 2.

\section{Fluid Tests}

Prior to each test with anti-icing treatment the uncontaminated wing case was measured to eliminate different daily changing factors on the results. As stated earlier the uncontaminated wing case was quite well repeatable however this was not the case after anti-icing treatment. The noise levels of measured lift coefficient after antiicing treatment were clearly higher than for the uncontaminated wing case up to the end of each test run.

Figure 9 illustrates the lift coefficient variation with time for a clean wing and anti-iced wing for DLR-F15. There is a clear difference between $\mathrm{C}_{1}$ values already during the take- off run. However, the significant phase is after the rotation.

Among the anti-icing treatment parameters studied for DLR-F15 wing section model the following ones did not show any observable effect on the results:

- $\quad$ one step treatment compared to two step treatment (30\% TI $+100 \% \mathrm{TII} / \mathrm{IV})$

Page 6 of 12
- $\quad$ initial mean thickness of the fluid layer - varied from $0.8 \mathrm{~mm}$ to $1.7 \mathrm{~mm}$

- temperature of the coolant tank (“fuel tank”) - varied from $-10{ }^{\circ} \mathrm{C}$ to $+7{ }^{\circ} \mathrm{C}$

The effect of fluid initial mean thickness has been reported to be negligible already in early 1990’s by Runyan et al [25].

Some of the parameters that had observable influence on lift degradation for wing section model DLR-F15 were:

- $\quad$ dilution of Type IV fluid with water (75\% TIV)

- $\quad$ acceleration time

Though the value of lift degradation at lift off is essential it is important to have some impression on the transiency after it. It is obvious that the lift loss due to the fluid should not persist. Flying with a reduced marginal at safety speed after the lift off should be limited in time. For this reason, the lift loss values following have been recorded also after the rotation.

Comparison between the lift degradation with neat Type IV and diluted Type IV (25 \% water) for DLR-F15 wing section is illustrated in Figure 10. The lift degradation is presented as a percentage (\%) of the clean wing lift coefficient while the time after rotation is measured from the point where the rotation has stopped (see Table 2). During the first 10 seconds after rotation the lift degradations are quite similar. After that the $\Delta \mathrm{C}_{1}$ stays above $3 \%$ for about 30 seconds for the diluted fluid while for the neat fluid induced lift loss continues to decrease steadily. This behavior suggests that the contribution of the secondary wave - a fluid wave that appears from the slat cavity after rotation - is not affected by fluid dilution whereas the residual fluid amount is. This appeared also in measured fluid residues after the test as the mean thickness of the diluted Type IV fluid was 2.6 times more than the thickness of the neat Type IV residues $(0.18 \mathrm{~mm}$ vs. $0.07 \mathrm{~mm})$.

Acceleration time is the time in which the wind tunnel speed is accelerated from idle speed to $60 \mathrm{~m} / \mathrm{s}$. Koivisto [26] discovered that

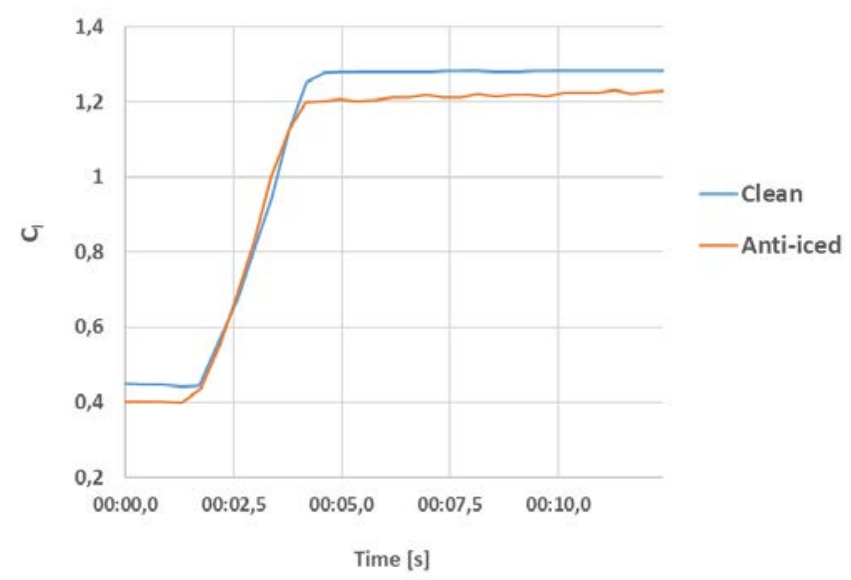

Figure 9. Lift coefficient variation with time for DLR-F15 wing section model. 
the acceleration time has a distinct almost linear effect on the fluid flow-off from the wing upper surface. This obviously seems to apply also to the lift degradation in present study. As seen in Figure 11 the lift degradation curve of a shorter acceleration time is shifted to the right for approximately the same amount of seconds as is the difference between the acceleration times. This result is intuitively understandable, because when the rotation is 5 seconds earlier it takes the same 5 seconds for the fluid to flow off after the rotation.

A short test series with Type I fluid (30\% TI + $70 \%$ water) treatment was also performed with the DLR F-15 wing section. The results showed that the lift degradation with Type I fluid was an order of magnitude less than for the thickened Type IV fluids and the time history of it was masked by the noise. The obvious cause for this was the very low viscosity of Type I fluid compared with the thickened anti-icing fluids. The air temperature on the test day $\left(1{ }^{\circ} \mathrm{C}\right)$ was simply too high to cause an observable effect on lift coefficient. To detect observable lift losses with Type I fluid the air temperature should be considerably below freezing point $\left(0{ }^{\circ} \mathrm{C}\right)$.

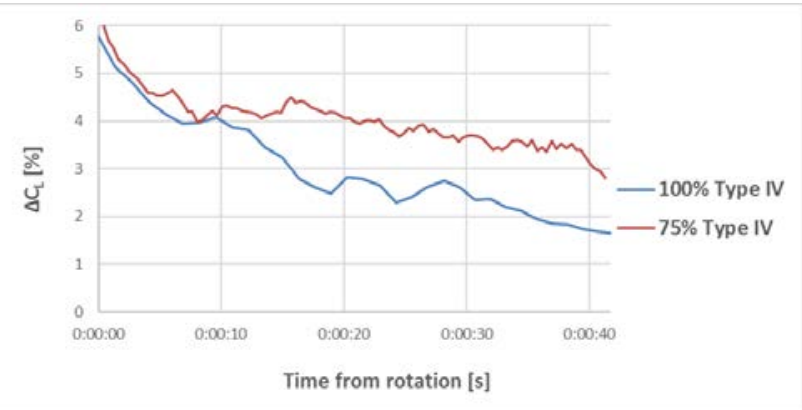

Figure 10. Comparison of neat and diluted Type IV fluid. for DLR-F15 wing section at $\mathrm{OAT}-3{ }^{\circ} \mathrm{C}$

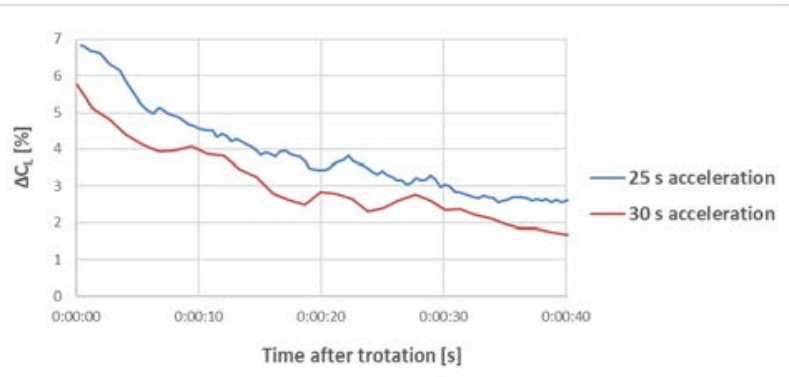

Figure 11. Effect of acceleration time on lift degradation for DLR-F15 wing section. $100 \%$ Type IV fluid at OAT $-3{ }^{\circ} \mathrm{C}$.

\section{Comparison with Other Wind Tunnel Tests}

Figure 12 compares the results of the present study with the data collected from NRC PIWT - facility results by Broeren and Riley [22]. The NRC PIWT-facility results are quite recent. In that study the wing section model however differs a lot from the one used in this study. There was a two element wing section with a slotted flap but no slat. That wing section was clearly thinner (9\%) than the DLR F15 but closer to the relative thickness of HL-CRM Mod wing section. The wing chord was $1.8 \mathrm{~m}$ which is considerably more than in the two other wing section models.
The speed - angle of attack sequence composed acceleration from 10 $\mathrm{m} / \mathrm{s}$ to $51 \mathrm{~m} / \mathrm{s}$ in less than $31 \mathrm{~s}$ with a take-off roll angle of attack of $2^{\circ}$ followed by $2.7 \%$ rotation at the speed of $51 \mathrm{~m} / \mathrm{s}$ to an angle of attack of $8^{\circ}$. The most relevant discrepancies between NRC- PIWT tests and the two other ones referred above are the differing wing section geometry, lower rotation speed and a higher Reynolds number $\left(9.210^{6}\right)$. However, the fluids applied in the NRC-PIWT tests are the same used in the present study which makes the comparison interesting. The mean value of lift losses in PIWT tests for this fluid seems to be quite similar with HL-CRM Mod wing section lift losses however at least 1 percentage point lower than the DLR-F15 results. Unfortunately, the present study HL-CRM Mod test temperatures do not match the two others.

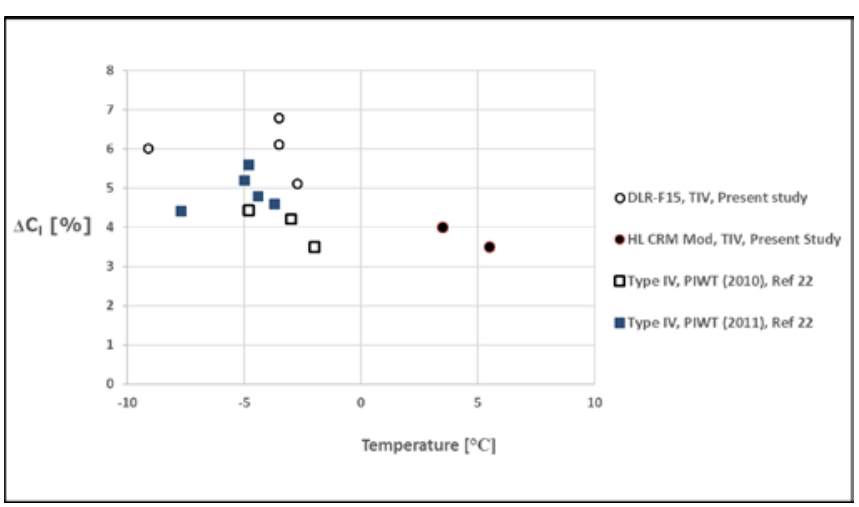

Figure 12. Comparison of lift degradation results of present study with results of Broeren and Riley [22] The fluid in [22] is the same in both data sets however from different batches (2010 and 2011)

\section{Cold Soaked Fuel Frost}

\section{Frost Creation}

To create the CSFF conditions within an acceptable time on the upper surfaces of the wing section models, the glycol mixture temperature inside the tanks should be preferably below $-10^{\circ} \mathrm{C}$. The methods to achieve cold tank temperatures for the two wing section models studied differed from each other. To get the DLR-F15 wing section model coolant tank area frosted the model was kept overnight in a deep freezer room. As the wing model was transported from the freezer and assembled to the wind tunnel test section the coolant tank warmed up inevitably from the initial temperature of $-25^{\circ} \mathrm{C}$ to around $-15^{\circ} \mathrm{C}$. During the transport and assembly of the model there was time for the coolant tank area to get frosted. The "natural" frost layer on the DLR-F15 wing model surface never grew up thicker than 0.15 $\mathrm{mm}$. To grow up the frost mean thickness on the tank area some moisture was added to the test section using a spray device. This device was utilized in front of the model with simultaneous low wind speeds in the tunnel $(5 \mathrm{~m} / \mathrm{s})$. By this method a frost thickness up to $0.65 \mathrm{~mm}$ was achieved. Tests were performed with both natural frost and frost with artificially added moisture.

For the HL- CRM Mod wing section model there was a separate cooling machine constructed to keep the tank temperature at $-18{ }^{\circ} \mathrm{C}$ before the wind tunnel test. A separate coolant circuit was designed inside the glycol mixture tank of the model. The coolant circuit was disconnected just prior to the wind tunnel run. By this method lower tank temperatures were achieved for longer time periods in the test

Page 7 of 12 
section which in turn led to considerably thicker natural layers of frost without separate added humidity.

The mean frost thicknesses measured before each test are collected in Table 3 and Table 4. It was difficult to achieve a uniform frost layer as seen from high standard deviation values, which is explained by the wing ribs and other under structure [Fig. 13]. The frost densities or liquid water contents of the frost were not measured in this study. The frost thicknesses on the DLR-F-15 model were measured approximately one hour after the model was brought into the windtunnel test section. The frost thicknesses on the HL-CRM Mod model were measured after a longer period of time of several hours. As shown in Table 4, there is a large range of thickness values. Since many environmental factors can contribute to the frost growth it is

Table 3. Frost thicknesses generated on the coolant tank upper surface before the tests for DLR F15 wing section. $\mathrm{k}$ is the mean frost thickness in mm. SD_k is the standard deviation of $\mathrm{k} . \mathrm{k} / \mathrm{c}$ is the frost thickness as a fraction of wing chord. SD_k/c is the standard deviation of $\mathrm{k} / \mathrm{c}$. RH is the Relative Humidity in the test section, TT is the coolant tank temperature just before the wind tunnel run, OAT is the wind tunnel air temperature. $\mathrm{N}$ indicates natural type of frost and AH added humidity type of frost.

\begin{tabular}{|l|l|l|l|l|l|l|l|}
\hline $\mathrm{k}$ [mm] & $\mathrm{SD} \_\mathrm{k}[\mathrm{mm}]$ & $1000 * \mathrm{k} / \mathrm{c}$ & $1000 *\left(\mathrm{SD} \_\mathrm{k} / \mathrm{c}\right)$ & $\begin{array}{c}\mathrm{TT} \\
{[\%]}\end{array}$ & $\begin{array}{l}\text { OAT } \\
{\left[{ }^{\circ} \mathrm{C}\right]}\end{array}$ & {$\left[{ }^{\circ} \mathrm{C}\right]$} & Type \\
\hline 0.093 & 0.022 & 0.142 & 0.035 & 78 & -14 & -5 & $\mathrm{~N}$ \\
\hline 0.525 & 0.375 & 0.808 & 0.577 & & -13 & -5 & $\mathrm{AH}$ \\
\hline 0.375 & 0.225 & 0.577 & 0.346 & & -11 & -5 & $\mathrm{AH}$ \\
\hline 0.133 & 0.093 & 0.205 & 0.143 & 76 & -15 & -1 & $\mathrm{~N}$ \\
\hline 0.650 & 0.187 & 1.000 & 0.288 & & -13 & -1 & $\mathrm{AH}$ \\
\hline 0.550 & 0.153 & 0.846 & 0.236 & & -10 & -1 & $\mathrm{AH}$ \\
\hline 0.154 & 0.151 & 0.237 & 0.233 & 86 & -15 & 4 & $\mathrm{~N}$ \\
\hline 0.475 & 0.263 & 0.731 & 0.405 & & -13 & 4 & $\mathrm{AH}$ \\
\hline
\end{tabular}

Table 4. Frost thicknesses generated on the coolant tank upper surface before the tests for HL-CRM Mod wing section. For symbols and abbreviations see Table 3. *Wing configuration flaps and slats retracted.

\begin{tabular}{|l|l|l|l|l|l|l|l|}
\hline $\begin{array}{l}\mathrm{k} \\
{[\mathrm{mm}]}\end{array}$ & $\begin{array}{l}\mathrm{SD}[\mathrm{k}] \\
{[\mathrm{mm}]}\end{array}$ & $1000^{*} \mathrm{k} / \mathrm{c}$ & $100{ }^{*}\left(\mathrm{SD} \_\mathrm{k} / \mathrm{c}\right)$ & $\begin{array}{l}\mathrm{RH} \\
{[\%]}\end{array}$ & $\begin{array}{l}\text { TT } \\
{\left[{ }^{\circ} \mathrm{C}\right]}\end{array}$ & $\begin{array}{l}\text { OAT } \\
{\left[{ }^{\circ} \mathrm{C}\right]}\end{array}$ & Type \\
\hline 0.253 & 0.052 & 0.405 & 0.084 & $(72)$ & -18 & 7 & $\mathrm{AH}$ \\
\hline 0.342 & 0.063 & 0.544 & 0.101 & 87 & -18 & 2 & $\mathrm{~N}$ \\
\hline 0.500 & 0.175 & 0.800 & 0.280 & 74 & -18 & -3 & $\mathrm{~N}$ \\
\hline 1.200 & 0.275 & 1,920 & 0.440 & 78 & -18 & 3 & $\mathrm{~N}$ \\
\hline $1.206^{*}$ & 0.410 & 1.929 & 0.656 & 65 & -18 & 8 & $\mathrm{~N}$ \\
\hline 1.389 & 0.176 & 2.222 & 0.282 & 65 & -18 & 7 & $\mathrm{~N}$ \\
\hline 1.500 & 0,176 & 2.400 & 0.282 & 78 & -18 & 3 & $\mathrm{~N}$ \\
\hline
\end{tabular}

\begin{tabular}{|l|l|l|l|l|l|l|l|}
\hline 2.044 & 0.572 & 3.272 & 0.916 & 81 & -18 & 1 & $\mathrm{~N}$ \\
\hline 2.250 & 1.222 & 3.600 & 1.955 & $(82)$ & -18 & 0 & $\mathrm{AH}$ \\
\hline
\end{tabular}

not possible to draw any definite conclusions regarding the effect of relative humidity or outdoor air temperature from these data. An important outcome of this investigation is that more precise control of the environmental conditional is needed in order to make a quantitative study on the factors influencing the growth of Cold Soaked Fuel Frost. These experiments were designed, in part, to evaluate aerodynamic impacts of real frost which led to some compromises in the ability to control the environmental conditions.

In spite of the challenges associated with precisely controlling all of the environmental conditions, the frost formations were considered to be representative of natural CSFF. The frost characteristics should be considered to be "full scale" despite the frost being grown on a subscale wing. The environmental conditions were not scaled in any way thus leading to frost thicknesses and morphology that should be consistent with frost growth on large-scale surfaces at similar environmental conditions. Therefore, the normalized frost thicknesses reported in Tables 3 and 4 were expected to be much larger than typical values for full-scale wings. There are no data known to the authors in the technical literature regarding frost thicknesses for CSFF. There are, however, some data reported for hoar frost that typically forms overnight in cold conditions. Bragg et al. [5] provide a reasonable summary of work up to and including the early 1990's. They suggested a k/c value equal to 0.00011 for "typical hoar frost" increasing to 0.00040 for "large frost." Using the $650 \mathrm{~mm}$ chord length for the DLR-F15 model, the equivalent range of dimensional frost thickness is 0.07 to $0.26 \mathrm{~mm}$. Bragg et al. [Ref. 5] do point out, however, that as frost grows it tends to build itself in layers which leads to an important difference between the total thickness and the roughness level. This is an important aerodynamic distinction because the overall thickness slightly modifies the airfoil or wing contour while the roughness level affects the aerodynamic penalties. Thus, it is important to quantify both the frost thickness and roughness level. That was the original intent of the 3D scanning and photogrammetry measurements. However, these methods were not fully implemented because of technical and programmatic challenges.

Due to structural differences in the two models, the frost layer appeared to concentrate on the DLR-F15 model strictly to the tank area (Fig. 13) whereas on the HL-CRM Mod model the whole main element of the model was covered by frost (Fig. 14). Only the composite slat and flap were clear of frost. On both models the lower side of the wing section was covered with even thicker frost layer. However, the lower side skin contamination does not affect the lift degradation at relevant angles of attack based on results by Bragg et al. [5].

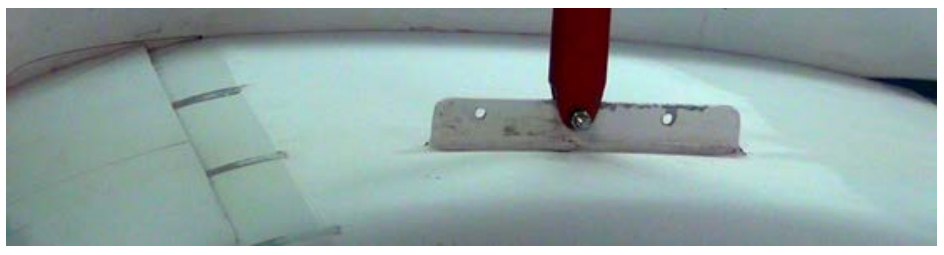

Fig. 13. Frost on DLR-F15 wing section mode

Page 8 of 12 


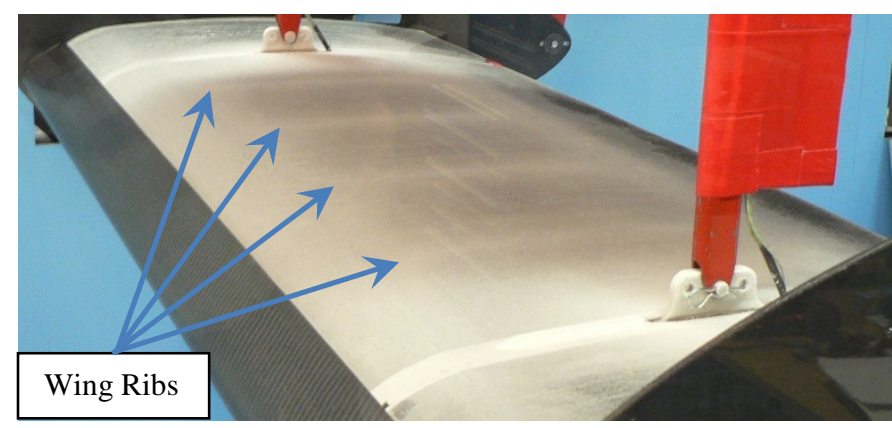

Fig. 14. Frost on HL-CRM-Mod wing section model.

\section{Lift Degradation after Rotation and Visual Observations}

The traditional method to assess the effect of frost on the wing section lift loss has been to simulate the frost by an equivalent "sand paper” type of fixed roughness. However, real frost is not a fixed roughness but reacts to the surrounding air stream. Depending on the air temperature there may be sublimation, melting and even selfshedding of frost particles. Part of these processes are present already during the take-off run on the ground but after the rotation they are clearly amplified. To figure out these processes and to assess the transiency of the effect of frost the lift losses were recorded not only at the point of lift off but after the rotation too. This gives a better possibility to compare the real frost and de/anti-icing treatment effects on lift loss after the lift off. Naturally the most relevant lift loss value is the one at the lift off.

Some samples of the lift degradation variations in time are collected into Figure 15 and Figure 16. Lift degradation results are presented as a percentage (\%) of the uncontaminated wing lift coefficient while the time after rotation is measured from the point where the rotation has stopped (see Table 2).

Figure 15 presents the lift degradation variations in time for both wing section models at temperatures close to or below freezing point. The slopes of these curves are quite gentle and almost linear, however clearly negative. At these temperatures there is practically no melting or sublimation though. This can be seen also from the video snapshots immediately after and $60 \mathrm{~s}$ after rotation - see Figure 17. There is only very slight darkening on the trailing edge area which implies some decrease in frost thickness. However, no signs of melting are present. The alteration in lift degradation and the change in the frost color shade may be due to shedding of the frost layer in the airstream.

Figure 16 presents lift degradation variations in time for temperatures clearly above the freezing point. The negative slopes are steeper and have a concave shape. The three lowest curves are for the first $30 \mathrm{~s}$ close each other for both wing section models. For DLR-F15 there are no measurements beyond $30 \mathrm{~s}$. In HL- CRM Mod tests it was revealed that the frost began to melt first behind the slat upper opening. However, the melted water froze back to ice at the point where the front spar is located. Obviously, the front spar was a cold spot due to its mass. The runback ice ridge was chord wise approximately $5 \mathrm{~mm}$ wide ranging over the whole span. The ice ridge remained on the surface about 50 to $60 \mathrm{~s}$ after which it shed from the surface along the span within a couple of seconds. Most probably it is this event that is observable in HL-CRM MOD - curves in Figure 16. There is a clear abrupt drop in lift degradation values at a point of time that matches well with the shed ice ridge event observed in the videotape.

Page 9 of 12

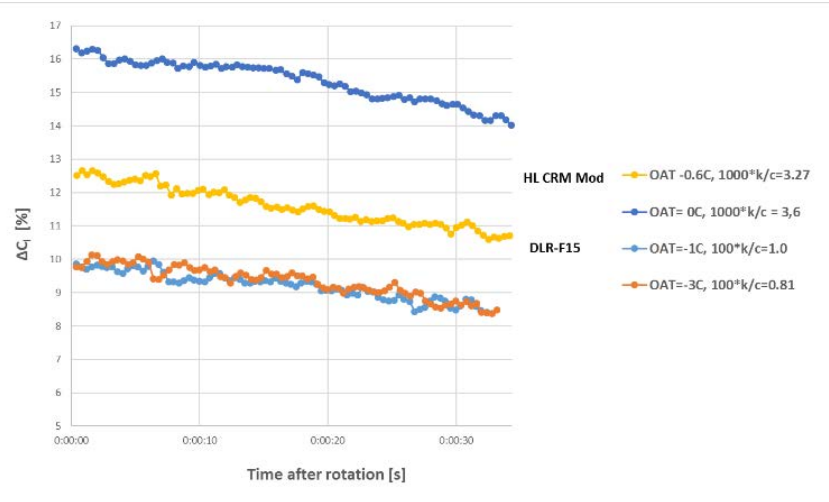

Figure 15. Lift coefficient degradation variation with time after rotation for temperatures at or below freezing point.

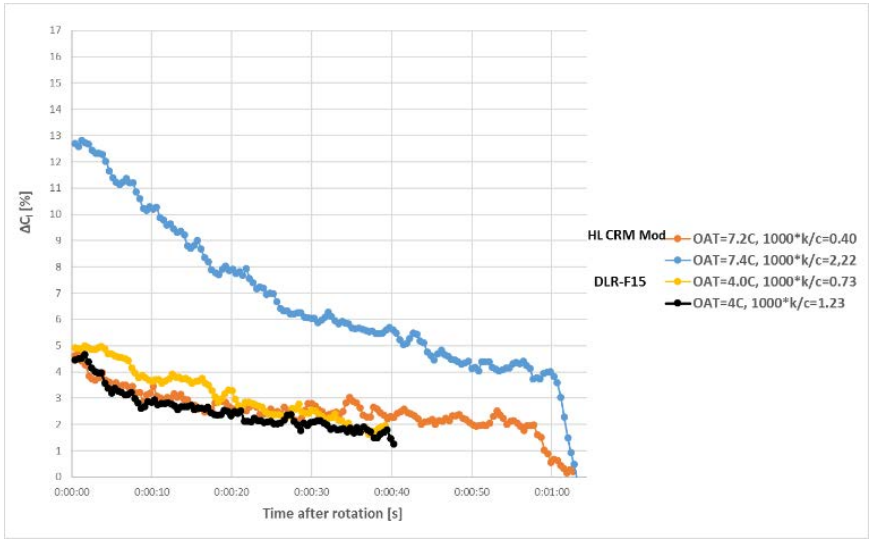

Figure 16. Lift coefficient degradation variation with time after rotation for four different frost (CSFF) thicknesses at a wind tunnel air temperature above freezing point.

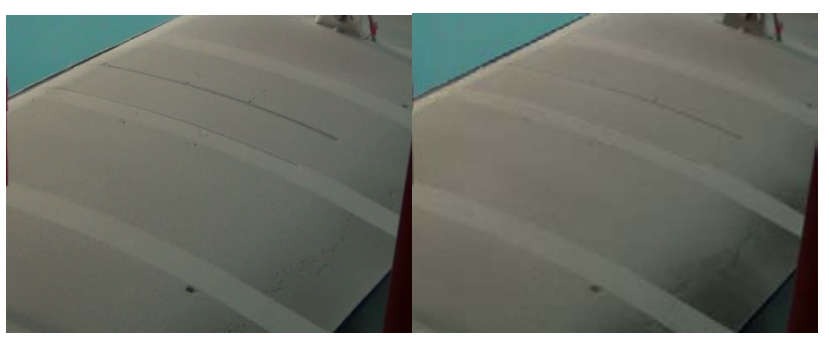

Figure 17. Video snapshot from the upper side of HL-CRM Mod wing section model just after rotation (left) and $60 \mathrm{~s}$ after rotation (right). Test section air temperature is $-0.6{ }^{\circ} \mathrm{C}$ and initial frost thickness $\mathrm{k} / \mathrm{c}=3.2710^{3}$. There is slight darkening observable at the trailing edge area.

The frost melting and sublimation process at an ambient temperature of $7.2^{\circ} \mathrm{C}$ is illustrated in video snapshot collection of Figure 18. It is difficult to distinguish melting from sublimation when the frost layer just turns darker in the video, but as the water starts to run on the surface it is obvious that melting is the dominant process in phase transition. When melting becomes dominant to sublimation the frost removal accelerates due to running water that sweeps over the frost.

The melting is visible in the third photograph from left in Figure 18. The edge of the frost layer bends from a straight line into a round shape as the melted water begins to run on the surface. Note that at this high temperature at least the sublimation begins already quite 


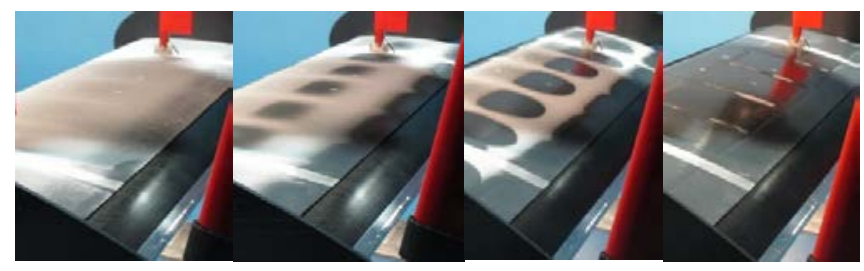

AoA $=0^{\circ} / \mathrm{U}=38 \mathrm{~m} / \mathrm{s}$

$\mathrm{AoA}=0^{\circ} / \mathrm{U}=57 \mathrm{~m} / \mathrm{s}$

AoA $=9.2^{\circ} / \mathrm{U}=60 \mathrm{~m} / \mathrm{s} \quad 30 \mathrm{~s}$ after rotation

Figure 18. Melting and sublimation process during a simulated take-off. Test section air temperature is $7.2{ }^{\circ} \mathrm{C}$ and initial frost thickness $\mathrm{k} / \mathrm{c}=0.4110^{-3}$. AoA is angle of attack and $\mathrm{U}$ wind tunnel speed. The third photograph from left is taken immediately after rotation. In this photograph the gradually increasing melting is revealed by the round shape of the downstream borderlines of the frost clear areas in the middle of the tank area.

early in the acceleration (take-off roll) phase. The melting process will however clearly accelerate after the rotation. When $30 \mathrm{~s}$ has elapsed from the rotation there are a few stripes of frost left located at the wing ribs area. The front spar ice-ridge separation is observable in a moving video, however it is difficult to catch it in still snapshot photographs.

\section{Frost as a Surface Roughness}

As stated earlier there are no previous studies considering the CSFF which is located in the fuel tank area only. There are however lots of studies on the effects of ice and frost type of surface roughness on wing aerodynamic properties when the roughness is either distributed over the whole wing area or alternatively concentrated to a short area on the leading edge (ice accretion) or slightly behind the leading edge area (runback type of ice). Lynch and Khodadoust [27] have provided an exhaustive review of the effect of ice and frost accretion on aircraft aerodynamics. In their review it becomes evident that the effect of roughness on lift degradation is more dominated by the position of the roughness than the total area of it. The well-known plot of Brumby [28] illustrates this behavior.

To assess the lift degradation due to the frost generated roughness the present study data have been collected in Figure 19 along with two of the plot lines of Brumby. The lift degradation values of this study are not directly comparable to the Brumby lines as the data from them are mostly collected from maximum lift coefficient loss.

Furthermore, the Brumby lines are collected from tests with a localized spanwise disturbance while the roughness in present study is distributed. However as emphasized above the distance of roughness from the leading edge is crucial.

There is some uncertainty in the frost thickness data of Figure 19 as at least in part of the wind tunnel runs frost thickness has already decreased somewhat during the acceleration phase before the rotation either by wear or by melting and sublimating. This applies especially at temperatures well above freezing point.

\section{Comparison of Fluids and Frost Results}

An anti-icing treatment is seldom an alternative for Cold Soaked Fuel Frost on the wing upper side, as this side is usually merely de-iced without any anti-icing treatment. However, comparing these two is not merely of academic interest. Especially a diluted Type IV fluid may be used to prevent the frost effects. Figure 20 illustrates the similar effects of certain amount of frost compared to anti-icing treatment for DLR-F15 wing section. Even if anti-icing treatment

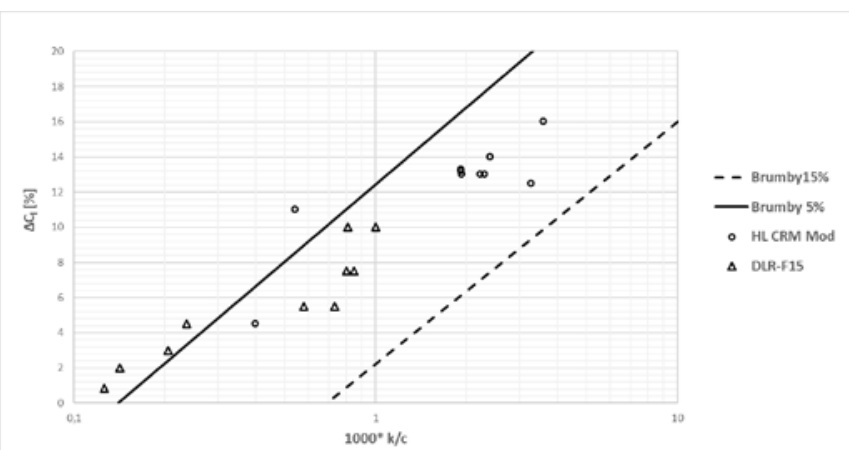

Figure 19. Frost induced initial lift degradation results of the present study compared with the results by Brumby [28]. The dotted line is created from results with localized spanwise roughness distribution at distance of $15 \%$ chord from the leading edge. The continuous line describes the results for a single roughness element at $5 \%$ chord distance from leading edge. The fuel tank area extends from $21.5 \%$ to $61.5 \%$ of chord for DLR-F15 and from 12 $\%$ to $65 \%$ of chord for HL-CRM MOD wing section.

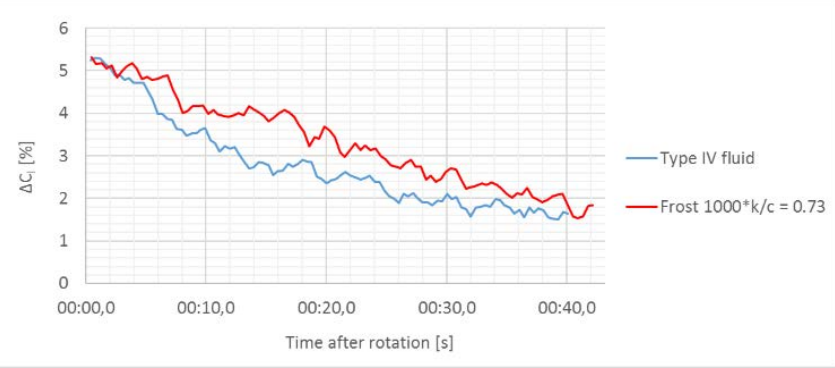

Figure 20. Comparison between the lift degradation caused by Cold Soaked Fuel Frost and anti-icing treatment at OAT $+4^{\circ} \mathrm{C}$ for DLR-F15 wing section.

is not considered as an alternative for Cold Soaked Fuel Frost it is operationally always considered as a safe option while the CSFF is according to present aviation safety practices normally to be removed.

In Figure 21 the comparison of CSFF and the two-step de-icing process is illustrated. These two are operationally realistic alternatives as the de-iced wing section was initially frost covered. Frost was de-iced by $50^{\circ} \mathrm{C}$ diluted (30\%) Type I followed by Type IV anti-icing treatment. The other curve presents an untreated CSFF frost. Figure 21 suggests that within certain conditions (OAT above freezing point and frost layer relatively thin) a two - step de-icing may result in worse lift degradation than an untreated CSFF on the wing.

\section{Summary/Conclusions}

The present study has compared the effects of anti-icing treatment and CSFF on lift degradation of two different 2D wing section models. Considering anti-icing treatment, the main findings were:

- $\quad$ Diluted Type IV fluid (75\% TIV) gave practically equal lift degradation with the neat Type IV during the first $10 \mathrm{~s}$ after rotation which after the diluted fluid caused the lift degradation to stay clearly higher than the neat fluid. The residual fluid layer was also found to be considerably thicker in the diluted fluid test.

- $\quad$ Acceleration time has a straightforward time shifting effect on the lift degradation. The lift degradation is delayed as

Page 10 of 12 


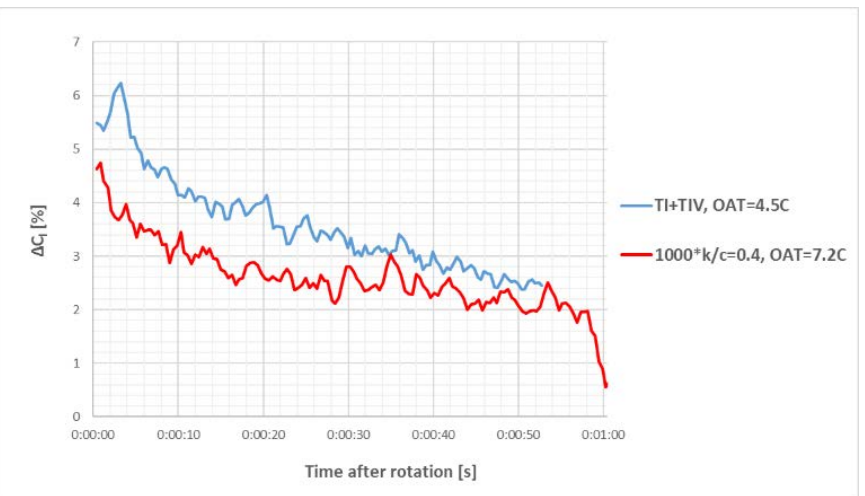

Figure 21. Comparison between the lift degradation caused by Cold Soaked Fuel Frost and two step de-icing treatment at OAT $4.5^{\circ} \mathrm{C}$ (Frost) and $7.2{ }^{\circ} \mathrm{C}$ $\left(30 \%, 50{ }^{\circ} \mathrm{C}\right.$ Type I + Type IV fluids) for HL-CRM Mod wing section.

many seconds as the time is shortened to reach wind tunnel speed of $60 \mathrm{~m} / \mathrm{s}$. This finding is consistent with results of Ref. 26.

Considering the Cold Soaked Fuel Frost tests the frost effect on lift degradation were demonstrated to be at least somewhat transient in nature even at below freezing temperatures. The effect of frost reduced with time and temperature after rotation. At air temperatures above freezing point part of the frost effect vanished already during take-off roll (acceleration) phase and the rest of the frost within $60 \mathrm{~s}$ after the rotation. The recovery from the Cold Soaked Fuel Frost induced lift degradation at temperatures above freezing point is caused by frost sublimation and melting. At subfreezing point there is probably also present some shedding of frost particles that reduces the frost effect on lift degradation. The lift recovery improves clearly with increasing air temperature.

An initial set of full-scale frost thickness measurements were reported for the two different $2 \mathrm{D}$ wing sections that is representative of full-scale Cold Soaked Fuel Frost. While this initial data set may be representative of frost formations in natural conditions, there were limitations regarding the ability to precisely control the environmental conditions in these experiments.

This study may be considered as a motivation for further research on this topic and the following issues should be addressed in the future:

- $\quad$ Frost density or liquid content and frost microstructure effect on lift degradation - in this study only the frost layer thickness was determined

- Improvements to the control and measurement of the environment variables affecting the frost growth.

- $\quad$ The fuel tank temperature effect on lift degradation. In this study temperatures between $-10{ }^{\circ} \mathrm{C}$ to $-18{ }^{\circ} \mathrm{C}$ were considered and there was no control for the fluid temperature once wind tunnel run started

- $\quad$ Theoretical background for frost sublimation and melting on a wing

When comparing the lift degradation due to CSFF and anti-icing fluids it is obvious that there may occur well defined ambient conditions in normal airliner operations where a strict "clean wing concept" does not really enhance safety but only results in additional fluids being introduced into the environment and with the associated costs.

\section{References}

[1] Terms of Reference for rulemaking task RMT.0118, Analysis of on-ground wing contamination effect on take-off performance degradation, European Aviation SAfety Agency, Issue 1, 21 Mar 2017, 6 p.

[2] Koivisto P., A Literature Review on Cold Soaked Fuel Frost Formation and Sublimation, Finnish Transport Safety Agency, Trafi Research Reports 6-2015, Helsinki, Finland, 2015.

[3] Ljungström B.L.G., Windtunnel investigation of simulated hoar frost on a two-dimensional wing section with an without high lift devices, Report FFA-AU-902, Stockholm, Sweden, April 1972.

[4] Kind R.J., Lawrysyn M.A., Aerodynamic Characteristics of Hoar Frost Roughness, AIAA Journal, Vol. 30, No. 7, July 1992..

[5] Bragg M.B., Heinrich D.C., Valarezo W.O, McGhee R.J., Effect of Underwing Frost on a Transport Aircraft Airfoil at Flight Reynolds Number, Journal of Aircraft Vol. 31, No. 6, 1994, pp. 1372, 1379 .

[6] Khodadoust A., Dominik C., Shin J., Miller D., Effect of In-flight Ice Accretion on the Performance of a Multielement airfoil, AHS/SAE international Icing Symposium, 1995, $10 \mathrm{p}$.

[7] Valarezo W.O., Lynch F.T., McGhee R.J., Aerodynamic Performance Effects due to Small Leading-Edge Ice (Roughness) on Wings and Tails, Journal of Aircraft, Vol. 30, No. 6, Nov.-Dec. 1993, PP. 807-812.

[8] Boer J.N., van Hengst J., Aerodynamic Degradation due to Distributed Roughness on High Lift Configuration, AIAA Paper 93-0028, 1993, 9 p.

[9] Koivisto P., Effects of Cold Soaked Fuel Frost on Lift Degradation during Simulated Take-off, Finnish Transport Safety Agency, Trafi Research Reports 42015, 2015, 24 p..

[10] Koivisto P., Preliminary Cold Soaked Fuel Frost Studies with CRM Wing Model, Finnish Transport Safety Agency, Trafi Research Reports 12-2016, Helsinki, Finland, 2016, 11 p.

[11] Lacy, D.S., Sclafani, A. J.: Development of the High Lift Common Research Model (HL-CRM): A Representative High Lift Configuration for Transonic Transports, 54th AIAA Aerospace Sciences Meeting 4-8 January 2016, San Diego, California, USA

[12] Wild, J.: "Experimental investigation of Mach- and Reynolds-number dependencies of the stall behavior of 2-element and 3- element high-lift wing sections”, AIAA 2012-0108, 50th AIAA Aerospace Sciences Meeting 
including the New Horizons Forum and Aerospace Exposition 09 - 12 January 2012, Nashville, Tennessee

[13] Code of Federal Regulations, Title 14 Aeronautics and Space, Volume 3, Chapter I, Subchapter G, Part 121, Federal Aviation Authority, Department of Transportation, Operating Requirements, Domestic, Flag, and Supplemental Operations, August 25, 2017.

[14] Commission Regulation (EU) No 965/2012, 5 October 2012, 148 p..

[15] Koivisto P., Soinne E., Kivekäs J., Anti-Icing Fluid Secondary Wave and Its Role in Lift Loss, Journal of Aircraft, published online 29 May2018, 9 p.

[16] Soinne E., Rosnell T., Aerodynamic, Laser scanning and Photogrammetric Measurements on Cold Soaked Fuel Frost, AIAA Paper 2018-3830, 2018, 12 p.

[17] Lee, S., Broeren, A. P., Kreeger, R. E., Potapczuk, M. G., and Utt, L., "Implementation and Validation of 3-D Ice Accretion Measurement Methodology,” AIAA Paper 2014-2613, June 2014.

[18] Broeren, A.P., Addy, Jr., H.E., Lee, S., Monastero, M.C., McClain, S.T., "Three-Dimensional Ice-Accretion Measurement Methodolgy for Experimental Aerodynamic Simulation,” Journal of Aircraft, Vol. 55, No. 2, Mar.-Apr. 2018.

[19] McClain, S.T., Vargas, M., Tsao, J.-C., and Broeren, A.P., "Ice Roughness and Thickness Evolution on a Business Jet Airfoil,” AIAA Paper 2018-3014, June 2018.

[20] Certification Specifications and Acceptable Means of Compliance for Large Aeroplanes, CS-25 Amendment 13, 10 June 2013.

[21] Hill E.G., Zierten T.A., Aerodynamic Effects of Aircraft Ground Deicing/Anti-Icing Fluids, Journal of Aircraft, Vol. 30, No.1 Jan-Feb 1993, page 24-34.

[22] Broeren A.P., Riley J.T., Review of the Aerodynamic Acceptance Test and Application to Anti-Icing Fluids Testing in the NRC Propulsion and Icing Wind Tunnel, NASA/TM-2012-216014, 2012, 34 p..

[23] Koivisto P., Effects of Anti-icing Treatment on Lift Degradation during Simulated Take-off, Finnish Transport Safety Agency, Trafi Publications 25-2013, Helsinki, Finland, 2013, 22 p..

[24] Standard Test Method for Aerodynamic Acceptance of SAE AMS 1424 and SAE AMS 1428 Aircraft Deicing/ Anti-icing Fluids”, AS5900 Rev.B , SAE International, 26 July 2007.

[25] Runyan, L.J., Zierten, T.A., Hill, E.G., Addy, H.E., "Lewis Icing Research Tunnel Test of the Aerodynamic Effects of Aircraft Ground Deicing/Anti-icing Fluids", NASA-TP 3238, 1992.
[26] Koivisto, P. “Anti-icing Fluid Flow off on a Wing Section During Simulated Taxi and Take-off”, AIAA 2013-2932, 5th atmospheric and Environments Conference, June 2427. 2013, San Diego CA.

[27] Lynch F.T., Khodadoust A., Effecs of Ice Accretio on Aircraft Aerodynamics, Progress in Aerospace Sciences 37 (2001) pp. 669-767,.

[28] Brumby RE. The effect of wing ice contamination on essential flight characteristics. AGARD CP-496,.

\section{Contact Information}

The lead author email address is pekka.koivisto@aalto.fi

\section{Acknowledgments}

The wind tunnel measurements were performed by Arteform Ltd. Laser scanning and analysis of the results was performed by NASA. Support from the U.S. Federal Aviation Administration and Finnish Transport Safety Agency is gratefully acknowledged.

\section{Definitions/Abbreviations}

\begin{tabular}{ll}
$\mathbf{C}$ & wing model chord \\
$\mathbf{C}_{\mathbf{L}}$ & wing lift coefficient \\
$\mathbf{k}$ & clean wing lift coefficient \\
$\mathbf{t}$ & frost roughness \\
$\mathbf{U}$ & frost thickness \\
$\mathbf{V}$ & wind tunnel velocity \\
$\mathbf{V}$ & rotation speed \\
$\boldsymbol{\alpha}$ & take-off safety speed \\
AAT & angle of attack \\
AGL & Aerodynamic Acceptance Test \\
CSFF & Above Ground Level \\
EASA & Cold Soaked Fuel Frost \\
OAT & European Aviation Safety Agency \\
OEI & Outside Air Temperature \\
\hline &
\end{tabular}

